\title{
COMPARISON OF INCIDENCE OF STERNAL WOUND DEHISCENCE AFTER SIMPLE INTERRUPTED STERNAL CLOSURE VS FIGURE-OF-EIGHT STERNAL CLOSURE IN PATIENTS OF CORONARY ARTERY BYPASS GRAFT SURGERY
}

\author{
Muhammad Ashfaq, Nasir Ali, Asif Mahmood Janjua, Naser Ali Khan, Ali Gohar Zamir, Rehana Javaid \\ Armed Forces Institute of Cardiology/National Institute of Heart Disease (AFIC/NIHD)/National University of Medical Sciences (NUMS) \\ Rawalpindi Pakistan
}

\section{ABSTRACT}

Objective: To compare the incidence of sternal wound dehiscence between simple interrupted vs. figure-of-eight sternal closure techniques for median sternotomy in patients undergoing coronary artery bypass graft surgery.

Study Design: Comparative prospective, randomized control trial.

Place and Duration of Study: Study conducted at Department of Cardiac Surgery, Armed Forces Institute of Cardiology Rawalpindi, from Apr to Dec 2019.

Methodology: A total of 206 patients were included in study. These patients were divided into two groups; group " $A$ ": cases which will undergo simple interrupted sternal wire closure technique (n1=103). Group "B": cases which will undergo figure-of-eight sternal wire closure technique (n2 = 103).

Results: There were no statistical difference in the pre-operative data of the patients. The incidence of sternal wound dehiscence in simple interrupted closure was $6.79 \%$ while in figure of eight closure technique it was noted to be $1.94 \%$. A statistically significant difference was noted in both the closure technique $(p<0.05)$.

Conclusions: Figure-of-eight sternal wire closure technique provides better strength and stability to sternum along with reduced incidence of sternal wound dehiscence as compare to simple interrupted wire closure.

Keywords: Coronary artery bypass graft, Dehiscence, Incidence, Sternal wound.

This is an Open Access article distributed under the terms of the Creative Commons Attribution License (http://creativecommons.org/licenses/by/4.0), which permits unrestricted use, distribution, and reproduction in any medium, provided the original work is properly cited.

\section{INTRODUCTION}

Median sternotomy is regarded as the gold standard approach for variety of open heart operations ${ }^{1}$. This approach has multiple complications related to patient risk factors, material used for closure and surgical technique. The predisposing factors for sternal wound dehiscence or sternal infection; chronic obstructive pulmonary disease, high body mass index, diabetes mellitus, old age and smoking ${ }^{2}$. According to Jaime Anger et al sternal wound infections were classified into four types as: Type I; loss of skin and subcutaneous tissue. Type II; bone is exposed. Type III; loss of bone tissue of sternum or ribs. Type IV; exposure of mediastinum ${ }^{3}$. When such complications are not recognized in the early postoperative period, they may lead to complete sternal dehiscence, infection either superficial or deep and subsequently full blown mediastinitis with

Correspondence: Dr Muhammad Ashfaq, Department of Cardiac Surgeon, AFIC/NIHD Rawalpindi Pakistan mortality rates ranging from $10 \%$ to $40 \% 4$. Superficial sternal wound infection ranges from $0.5 \%$ to $8 \%$ while deep sternal wound infection reported to be less than $1 \%^{5}$.

Incidence of sternal dehiscence and infection can be reduced by using a reliable closure technique $^{2}$. Therefore, many surgical techniques introduced for stabilizing and closure of sternum after median sternotomy have been utilized among which most popular and routinely used are; simple interrupted and figure-of-eight wire closure$^{1}$. The aim of all techniques is to achieve rigidity and strength of sternum. The figure-ofeight wiring possesses more advantages over simple interrupted because it distributes sternal stress over an increased area and limits longitudinal displacement ${ }^{6}$. According to a study conducted at Punjab Institute of Cardiology they reported a reduced incidence of sternal wound dehiscence $(2 \%)$ in patients with figure-of-eight sternal closure after coronary artery bypass surgery through median sternotomy ${ }^{1}$. Another study 
conducted at Pakistan Institute of Medical Sciences Islamabad showed that there is no statistically significant difference in sternal dehiscence between simple and figure-of-eight closure techniques because sternal dehiscence in simple interrupted was reported to be $7.5 \%$ and in figure-ofeight $8.3 \%^{4}$. In study conducted at Iran reported almost same results of sternal dehiscence in simple interrupted $(2.5 \%)$ vs figure-of-eight $(2.5 \%)$ sternal closure7. Till now no single method of sternal closure is regarded as standard therefore more research work is needed. Our study is one step to find out which closure method has reduced incidence of sternal dehiscence.

Rationale: Sternal wound dehiscence is the worst complication of median sternotomy with increased mortality and morbidity, which can be reduced by using standard sternal closure technique. This study would assess the frequency of sternal wound dehiscence in simple interrupted vs figure-of-eight closure technique, thus will help in devising a standard protocol for sternal closure. The results will add to the existing body of knowledge and may be used by practitioners in instituting informed evidence based practice.

To compare the incidence of sternal wound dehiscence between simple interrupted vs figure of eight sternal closure techniques for median sternotomy in patients undergoing coronary artery bypass graft surgery.

\section{METHODOLOGY}

A Randomized control trail in Department of Adult Cardiac Surgery, Armed Forces Institute of Cardiology and National Institute of Heart Diseases, Rawalpindi, were conducted from April 2019 to December 2019. Patient of any age \& gender, booked for elective Coronary artery bypass surgery were included. Patient with Bilateral internal mammary artery harvesting, chronic renal failure (Glomerular filtration rate less than $45 \mathrm{ml} /$ $\min / 1.73 \mathrm{~m}^{2}$ for more than three months i.e. Class III-B Chronic renal failure), Anemic patient with Hemoglobin less than $8 \mathrm{mg} / \mathrm{dl}$, moderate (forced expiratory volume i.e. FEV1 less than 50\%) and severe (forced expiratory volume i.e. FEV1 less than $30 \%$ ) chronic obstructive pulmonary disease, Body Mass Index (BMI) less than 18 (regarded as malnutrition), Multiple sternal fracture during closure or opening of sternum, Redo Coronary artery bypass, Re-explorations and Re-closures after open heart surgery, Left Ventricular Ejection Fraction of Less or equal to 30\%, Robicsek Procedure in which parasternal steel wires are passed in both halves of sternum. Two hundred and six patients fulfilling the inclusion criteria, after consent were grouped either for simple interrupted closure (group A) or figure-of-eight closure (group B) via lottery method. The demographic data including patient's age, gender, BMI \& comorbidities were noted. Cardiopulmonary bypass with body cooling temperature of 32-34oC, cardiac diastolic arrest via hyperkalemic blood cardioplegia used as per routine protocol. In all cases, stainless-steel no.5 wires were used for approximation of sternal halves utilizing either simple interrupted or figure-of-eight techniques. In the figure-of-eight four steel wires pierced the sternum parasternally among which three were passed through body of sternum and one through manubrium. In simple interrupted closure technique, we placed 3 steel wires in manubrium and 5 steel wires in lateral sternal borders of the body of sternum. After sternal closure muscle and fascial layers were approximated with vicryl " 0 " and skin closure done in subcuticular manner by vicryl 3/0. After surgery patients shifted to intensive care unit then high dependency unit and finally to postoperative ward from where they were discharged for home. First dressing after surgery was opened after 48 hours by the investigator and chest X-ray performed. Signs of infection/ inflammation were noted along with signs of sternal dehiscence clinically and on chest X-ray. Follow up done after one week, four weeks and after 8 weeks to detect signs of sternal wound dehiscence. Final outcome was determined after 8weeks.

\section{RESULTS}

The demographic data of the enrolled patients presented in table-I. The mean age in group A was $51 \pm 13$ years while in group B it 
was $53 \pm 17$ years. No Statistically significant difference was found in age, gender \& Body mass Index ( $p$-value>0.05). Among these patients $24.27 \%$ in group A \& $26.21 \%$ in group B were microbial growth. Table-III showed incidence of sternal dehiscence among group A $(6.79 \%)$ \& group B $(1.94 \%)$, which is statistically significant $(p=0.011)$.

Table-I: Demographics and pre-operative data of patients.

\begin{tabular}{|c|c|c|c|c|}
\hline \multicolumn{2}{|c|}{ Characteristics } & $\begin{array}{l}\text { Simple Interrupted Sternal } \\
\text { Closure }(\mathrm{n} 1=103)\end{array}$ & $\begin{array}{l}\text { Figure-of-Eight Sternal } \\
\text { Closure (n2=103) }\end{array}$ & $p$-value \\
\hline \multicolumn{2}{|l|}{ Age (Years) } & $51 \pm 13$ & $53 \pm 17$ & 0.13 \\
\hline \multirow{2}{*}{ Gender } & Male & $55(53.39 \%)$ & $59(57.28 \%)$ & \multirow{2}{*}{0.22} \\
\hline & Female & $48(46.61 \%)$ & $44(42.72 \%)$ & \\
\hline \multirow{3}{*}{ BMI } & $20-24$ & 21 & 25 & \multirow{3}{*}{0.26} \\
\hline & $25-30$ & 53 & 44 & \\
\hline & $>30$ & 29 & 34 & \\
\hline \multicolumn{2}{|l|}{ Diabetes } & $25(24.27 \%)$ & $27(26.21 \%)$ & 0.09 \\
\hline \multicolumn{2}{|l|}{ Hypertension } & $29(28.15 \%)$ & $31(30.09 \%)$ & 0.11 \\
\hline \multicolumn{2}{|l|}{ Smoking } & $21(20.38 \%)$ & $23(22.33 \%)$ & 0.37 \\
\hline \multirow{3}{*}{$\begin{array}{l}\text { Ejection } \\
\text { Fraction (\%) }\end{array}$} & $31-40 \%$ & 11 & 14 & \multirow{3}{*}{0.076} \\
\hline & $41-50 \%$ & 33 & 28 & \\
\hline & $>50 \%$ & 59 & 61 & \\
\hline
\end{tabular}

Table-II: Post-operative data.

\begin{tabular}{l|c|c|c}
\hline Variables & $\begin{array}{c}\text { Simple Interrupted } \\
\text { Sternal Closure (n1=103) }\end{array}$ & $\begin{array}{c}\text { Figure-of-Eight Sternal } \\
\text { Closure (n2=103) }\end{array}$ & $p$-value \\
\hline $\begin{array}{l}\text { Superficial Surgical Wound } \\
\text { Infection (SSWI) }\end{array}$ & $9(8.73 \%)$ & $5(4.85 \%)$ & 0.011 \\
\hline $\begin{array}{l}\text { Micro-organism on culture (in } \\
\text { case of discharge) }\end{array}$ & $5(4.85 \%)$ & $2(1.94 \%)$ & 0.021 \\
\hline Table-III: Sternal dehiscence. & $\begin{array}{c}\text { Simple Interrupted } \\
\text { Sternal Closure (n1=103) }\end{array}$ & $\begin{array}{c}\text { Figure-of-Eight Sternal } \\
\text { Closure (n2=103) }\end{array}$ & \multirow{2}{*}{$p$-value } \\
\hline Sternal Dehiscence & $7(6.79 \%)$ & $2(1.94 \%)$ & 0.011 \\
\hline Yes & 96 & 101 & \multirow{2}{*}{} \\
\hline No & &
\end{tabular}

diabetics, $28.15 \%$ \& $30.09 \%$ were hypertensive in group A \& B respectively. 20.38\% were smokers in group A \& $22.33 \%$ in group B. Ejection Fraction of the patients included in the study was found to be statistically non-significant.

Post-operatively patients were observed for signs of infection/inflammation \& sternal dehiscence during admission/follow up. Table-II showed that $8.73 \%$ of the patients in group $\mathrm{A}$ had superficial sternal wound infection in comparison to $4.85 \%$ in group $B$, which is statistically significant $(p=0.011)$. Swab for culture \& sensitivity was sent for those patients who had discharge from wound. In group A $4.85 \%$ showed growth of micro-organism while in group B $1.94 \%$ had

\section{DISCUSSION}

Median sternotomy is the gold standard approach for exposure of heart for almost all cardiac surgical procedures ${ }^{1}$. This technique gave a very good exposure but can end-up in adverse outcomes therefore, sternal wound dehiscence is the worst complication of median sternotomy with increased mortality and morbidity ${ }^{8}$, which can be reduced by using standard sternal closure technique. Different studies have reported mortality that mortality \& morbidity associated with sternal dehiscence ranges from $10-40 \% 4$. The aim of this study is to determine the frequency of sternal wound dehiscence in simple vs figure-ofeight wiring technique. 
In different studies some risk factors of sternal wound dehiscence were established like uncontrolled diabetes mellitus, hypertension, renal dysfunction, smoking, chronic cough, obesity, bilateral Internal mammary artery harvesting, prolonged ventilation and poor left ventricular ejection fraction (less than $30 \%)^{9}$. In our study we tried to minimize the effects of these risk factors by matching and excluding those patients so that we can purely determine the significance of the surgical technique, best for sternal closure, with minimal complications.

In our study the overall incidence of sternal wound dehiscence was $4.36 \%$ among which in group A it was $6.79 \%$ while in group B $1.94 \%$, which was statistically significant $(p<0.05)$. Out of $4.36 \%, 3.39 \%$ had microbial growth on culture while $0.97 \%$ were due to mechanical cause. Ramzisham et al reported that $1.5 \%$ of sternal dehiscence showed microbial growth (more in simple wire technique) ${ }^{11}$. Our data is comparable to the internationally available data showing that the incidence of sternal wound dehiscence is low in figure-of-eight vs simple wire technique. A study conducted at Punjab Institute of Cardiology showed reduced incidence of sternal wound dehiscence in figure-of-eight vs simple wire closure technique $(2 \% \text { vs } 8 \%)^{1}$. Kiessling et al reported sternal dehiscence of $2 \%$ in figure-of-eight while $12 \%$ in simple wire closure technique ${ }^{10}$. In our study no mortality was noted in both the groups. Ramzisham et al reported $11.1 \%$ mortality after sternal wound dehiscence ${ }^{11}$. The incidence of infective mediastinitis in our study was $4.36 \%$ while in internationally available data it ranges from 1$5 \%{ }^{1}$. The study of Ramzisham et al11, Mirhosseini et $a^{12}$ and Iqbal et al showed that there is no statistically significant difference between figureof-eight vs Simple interrupted sternal closure. Krejca \& Colleagues proposed that simple interrupted wire technique provides good fixation of the sternal halves while figure-of-eight provides better strength ${ }^{13}$. The sternal dehiscence can be easily diagnosed clinically by sternal click/instability and confirmed by displacement of sternal wires on chest radiograph. Similar findings were shown in a study conducted by Javed Iqbal et al 4 . Schimmer et al documented in there study that Robicsek technique preferably prevent sternal dehiscence and deep sternal wound infection ${ }^{14}$. Another study conducted in which the significance of using sternal wires was compared with sternal cables in terms of sternal dehiscence, DSWI or mediastinitis, reported no statistical significant difference in these two methods ${ }^{15}$. Neena et al recommended figure of eight closure in fragile sternum while simple closure technique in normal healthy bone ${ }^{16}$. Almdahl et al conducted a study on 7835 patients for sternal dehiscence after figure of eight \& simple wire technique, concluded that sternal dehiscence was significantly low in figure-of-eight wiring technique as compare to simple wire closure ${ }^{17}$. In our study those patients of sternal wound dehiscence were managed by Intravenous Antibiotics \& Rewiring by using Robicsek Technique along with re-enforcement via myocutaneous flap of pectoralis muscle. Robicsek Technique provided excellent sternal approximation after reoperation for sternal dehiscence ${ }^{18}$.

\section{CONCLUSION}

As statistically proved from our study that the outcome of figure-of-eight sternal closure technique is better than simple interrupted wire closure in terms of sternal dehiscence. But before generalizing the findings of our study we would recommend that further studies should be conducted on larger scale in different hospitals of the country, in different groups of patients to establish and suggest the most efficient and low risk closure technique for sternum after median sternotomy.

\section{CONFLICT OF INTEREST}

This study has no conflict of interest to be declared by any author.

\section{REFERENCES}

1. Abbas S, Gul S, Abbas A, Iqbal M, Khan T, Khan JS. Figure of eight sternal closure vs simple interrupted sternal closure in reducing sternal dehiscence in patients with coronary artery bypass grafting. Pak Heart J 2017; 50(2): 94-99.

2. Ozen Y, Sarikaya S, Rabus MB, Gunay D, Aksoy E, Dedemoglu M, Kirali K. Comparison of sternal wires and sternal cable in 
closure of sternum during cardiac surgery. Cardiovascular Surg Intervent 2014; 1(2): 41-44.

3. Anger J, Dantas DG, Arnoni RT, Farsky PS. A new classification of post-sternotomy dehiscence. Braz J Cardiovasc Surg 2015; 30(1): 114-18

4. Iqbal J, Khan F, Rafique M, Abbasi S. Comparison of simple wire and figure of eight techniques in terms of development and outcome of sternal dehiscence in patients undergoing coronary artery bypass graft surgery. Ann Pak Inst Med Sci 2014; 10(4): 210-16.

5. Lazar HL, Salm TV, Engelman R, Orgill D, Gordon S. Prevention and management of sternal wound infections. J Thoracic Cardiovascul Surg 2016; 152(4): 962-72.

6. Bhagwat KA, Stephens GC, Chakaramakkill MJ, Ratinam R. Modified tightening for figure of eight sternal wiring closure. Innovations 2015; 10(5): 368-69.

7. Mirhosseini SJ, Sayegh SAH, Manshadi SMYMP, Naderi N, Hadibarhaghtalab M, Lotfaliani MR. Figure of eight wire sternal closure technique can reduce post-open cardiovascular surgery chest re-exploration and pain scores in diabetic patients with severe obesity. Intl J Clini Exper Med Sci 2015; 1(3): 38-41.

8. Hirose H, Yamane K, Youdelman BA, Bogar L, Diehl JT. Rigid sternal fixation improves postoperative recovery. Open Cardiovasc Med J 2011; 5: 148-52.

9. Tekumit H, Cenal AR, Tataroglu C, Uzunk, Akinci E. Comparison of figure of eight \& simple wire sternal closure technique in patients with non-microbial sternal dehiscence. Anadolu Kardiyol Derg 2009; 9: 411-16.

10. Kiessling AH, Isgro F, Weisse U, Moltner A, Saggau W, Boldt J. Advance sternal closure to prevent dehiscence in obese patients.
Ann Thorac Surg 2005; 80: 1537-39.

11. Ramzisham AR, Raflis AR. Figure-of-eight vs Interrupted sternal wire closure of median sternotomy. Asian Cardiovasc Thorac Ann 2009; 17: 587-91.

12. Mirhosseini SJ, Sayegh SAH, Manshadi SMYMP, Naderi N, Hadibarhaghtalab M, Lotfaliani MR. Figure of Eight wire sternal closure technique can reduce post-operative cardiovascular surgery chest re-exploration \& pain score in diabetic patients with severe obesity. Int J Clin Exp Med 2015; 1(3): 38-41.

13. Krejca M, Szmagala P, Skarysz J, Bochenek K, Ulczok R, Bis J, et al. Force distribuation in wire sternum sutures; the consequences of sternal closure rigidity. Med Sci Monit 2003; 9: 134-44.

14. Schimmer C, Sommer SP, Bensch M, Bohrer T, Aleksic I, Leyh R. Sternal closure techniques \& post-operative wound complications in elderly patients. Euro J Cardiothoracic Surg 2008; 34: 132-38.

15. Dunne B, Murphy M, Skiba R, Wang X, Ho K, Larbalestier R, et al. Sternal cables are not superior to traditional sternal wiring for preventing deep sternal wound infection. Interact Cardiovasc Thorac Surg 2016; 22: 594-98.

16. Neena A, Nappi F, Dougal J. Sternal wound closure in current era: the need of tailored approach. Gen Thorac Cardiovac Surg 2019; 67(11): 907-16.

17. Almdahl SM, Halvorsen P, Veel T, Rynning SE. Avoidance of non-infectious sternal dehiscence: figure of eight is superior to straight wire closure. Scand Cardiovasc J 2013; 47(4): 247-50.

18. Lafci G, Yasar E, Cicek OF, Irdem A, Uzun A, Yalcinkaya A. A novel modified robicsek technique for sternal closure: double check. Asian Cardiovasc Thorac Ann 2014; 22(6): 758-60. 